\title{
Physico-chemical characterisation and biological evaluation of I 88-Rhenium colloids for radiosynovectomy
}

\author{
Ma Cristina Ures*1, Eduardo Savio ${ }^{1}$, Antonio Malanga ${ }^{2}$, Marcelo Fernández ${ }^{3}$, \\ Andrea Paolino ${ }^{1}$ and Javier Gaudiano ${ }^{4}$
}

Address: ${ }^{1}$ Cátedra de Radioquímica. Facultad de Química. Universidad de la República. Montevideo, Uruguay, ${ }^{2}$ Cátedra de Farmacotecnia. Facultad de Química. Universidad de la República. Montevideo, Uruguay, ${ }^{3}$ Cátedra de Inmunología. Facultad de Química. Universidad de la República. Montevideo, Uruguay and ${ }^{4}$ Centro de Medicina Nuclear. Hospital de Clínicas. Facultad de Medicina. Universidad de la República. Montevideo, Uruguay

E-mail: Ma Ures* - cures@fq.edu.uy; Eduardo Savio - esavio@fq.edu.uy; Antonio Malanga - amalanga@fq.edu.uy; Marcelo Fernández - mfernandez@fq.edu.uy; Andrea Paolino - apaolino@fq.edu.uy; Javier Gaudiano - gaudiano@hc.edu.uy

${ }^{*}$ Corresponding author

Published: 14 October 2002

BMC Nuclear Medicine 2002, 2:I

This article is available from: http://www.biomedcentral.com/147I-2385/2/I

(C) 2002 Ures et al; licensee BioMed Central Ltd. This article is published in Open Access: verbatim copying and redistribution of this article are permitted in all media for any purpose, provided this notice is preserved along with the article's original URL.
Received: 14 August 2002

Accepted: 14 October 2002

\begin{abstract}
Background: Radiosynovectomy is a type of radiotherapy used to relieve pain and inflammation from rheumatoid arthritis. In this study, I88-Rhenium ( ${ }^{188} \mathrm{Re}$ ) colloids were characterized by physical and biological methodologies. This was used to assess which parameters of the kit formulation would be the basis in the development of a more effective radiopharmaceutical for synovectomy. Intraarticular injection in knees of rabbits assessed cavity leakage of activity.

Methods: The physical characteristics of tin (Sn) and sulphur (S) colloids were determined to assess the formulation with suitable properties. Particles were grouped in three ranges for analyzing their distribution according to their number, volume and surface. The ideal particle size range was considered to be from 2 to 10 microns. Membrane filtration and laser diffraction characterization methodologies were used.

Results: While membrane filtration could give misleading data, laser diffraction proportions more reliable results. The $\mathrm{Sn}$ colloid showed a better distribution of particle volume and surface than $\mathrm{S}$ colloid, in the 2 to 10 microns range. The ${ }^{188} \mathrm{Re}-\mathrm{Sn}$ colloid was obtained with a radiochemical purity higher than $95 \%$ after 30 minutes of autoclaving. While Sn colloid kit stability was verified for 60 days, the ${ }^{188} \mathrm{Re}-\mathrm{Sn}$ preparation was stable in the first $24 \mathrm{hrs}$. No significant intrabatch variability (n $=3$ ) was detected. Biodistribution and scintigraphic studies in rabbits after intraarticular injection showed relevant activity only in knee, being $90 \%$ at 48 hours.
\end{abstract}

Conclusion: The ${ }^{188} \mathrm{Re}-\mathrm{Sn}$ colloid is easy to prepare, is stable for 24 hours and shows minimal cavity leakage after intraarticular injection into rabbit knees, suggesting this radiotherapeutical agent has suitable physical properties for evaluation for joint treatment in humans.

\section{Background}

Radiosynovectomy is a radiotherapy, which has been used for more than 40 years to relieve pain and inflammation from rheumatoid arthritis (RA). It was developed as an al- 
ternative to surgical synovectomy [1-3]. The procedure consists in the injection of a beta-emitting radionuclide into the joint capsule $[4,5]$, where it remains in contact with the synovial membrane or synovium. The intraarticular-administered radiopharmaceutical is then phagocyted by the lining cells, which are on the synovial surface. While the radionuclide is decaying the absorbed dose is being given to the synovium.

${ }^{188}$ Rhenium is an attractive radionuclide for radiosynovectomy because of its suitable chemistry, $\mathrm{t}_{1 / 2}=16.9$ hours and average beta energy of $776 \mathrm{keV}\left(\mathrm{E}_{\max }=2.11\right.$ $\mathrm{MeV}, 79 \%)$. These properties enable knee treatment due to its maximal tissue penetration of $11 \mathrm{~mm}$, and its mean range of $3.8 \mathrm{~mm}[6,8] .{ }^{188} \mathrm{Re}$ decays to the stable $188 \mathrm{Os}$, with a gamma ray emission of $155 \mathrm{KeV}(15 \%)$ that is suitable for image acquisition. This fact allows target uptake evaluation, as well as the estimation of the absorbed radiation dose. Besides this, rhenium-188 is readily available on routine bases from the tungsten-188/rhenium-188 generator system $[9,10]$, which has a useful shelf-life of several months.

The ideal radiopharmaceutical radiolabeled with ${ }^{188} \mathrm{Re}$ for radiosynovectomy should meet the following requirements:

a) ${ }^{188}$ Rhenium should be attached to a particle that is sufficiently small to be phagocytized, but not so small that it might leak from the joint before being phagocytized; the appropriate size range is usually considered to be from 2 to 10 microns;

b) the binding between the radionuclide and the particle should be irreversible throughout the course of the radiotherapy, which, in turn, is determined by the physical half-life of the radionuclide;

c) the radiolabeled particles should be distributed homogeneously in the joint without initiating an inflammatory response.

Taking into account a previous study [11], which showed that colloidal preparations are the ones that best fulfil these requirements, the ${ }^{188} \mathrm{Re}-\mathrm{Sn}$ and $188 \mathrm{Re}-\mathrm{S}$ colloids were prepared.

The radiocolloid preparations were studied by two methodologies - laser diffraction and membrane filtration - in order to analyze which physical parameters were more relevant to accomplish the characteristics described above.

In this study, the ${ }^{188}$ Re colloids were characterized by physical and biological methodologies to assess which parameters of the kit formulation enable to achieve a better radiopharmaceutical for synovectomy. The ${ }^{188} \mathrm{Re}-\mathrm{Sn}$ colloid was evaluated in preliminary studies by evaluating capsule leakage by gamma camera imaging after intraarticular administration in rabbit knees.

\section{Methods}

\section{Colloids kit composition}

The ${ }^{188}$ Re-Sn colloid was prepared according to the following formulation, modified from that previously reported [11]

$10 \mathrm{mg} \mathrm{SnCl}{ }_{2} \cdot 2 \mathrm{H}_{2} \mathrm{O}$

\section{$0.5 \mathrm{~mL} \mathrm{HCl} 0.1 \mathrm{~N}$}

$2 \mathrm{mg}$ ascorbic acid

One per cent w/w Tween $80^{\circledR}$ in experiments where indicated

$\mathrm{N}_{2}$ atmosphere

The ${ }^{188}$ Re-S colloid kit was prepared with the following composition [6]:

$40 \mathrm{mg} \mathrm{Na}{ }_{2} \mathrm{~S}_{2} \mathrm{O}_{3}$

$4.8 \mathrm{mg}$ EDTA disodium salt

$0.8 \mathrm{mg} \mathrm{KReO}_{4}$ carrier

$1.5 \mathrm{~mL} 0.9 \%$ saline solution

pH was adjusted to 1 with $\mathrm{HCl} 0.1 \mathrm{~N}$

All reagents used were analytical grade

\section{Preparation and control}

Sn colloid preparation was carried out with the following technique: a kit was heated (by autoclave or water bath) for preset times $(15,30,60$ or $90 \mathrm{~min})$. Different final volumes were assayed with the addition of $0.9 \%$ saline solution $(0,0.5,1.0$ or $1.5 \mathrm{~mL})$. Two tin kit formulations were tested: with or without the tensoactive agent $(1-\% \mathrm{w} / \mathrm{w}$ Tween $80^{\oplus}$ ).

\section{Labeling procedure and quality control}

The ${ }^{188}$ Re were eluted from a ${ }^{188} \mathrm{~W} /{ }^{188}$ Re generator (MAP Technologies, Finland).

The 188Re-Sn colloid was labeled by the addition of 500 $\mu \mathrm{Ci}(18.5 \mathrm{MBq})$ of ${ }^{188} \mathrm{ReO}_{4}{ }^{-}$to the kit formulation described before, then it was autoclaved for $1 \mathrm{~h}$. pH was adjusted to 8.0 with a phosphate buffer $0.2 \mathrm{M}$. 

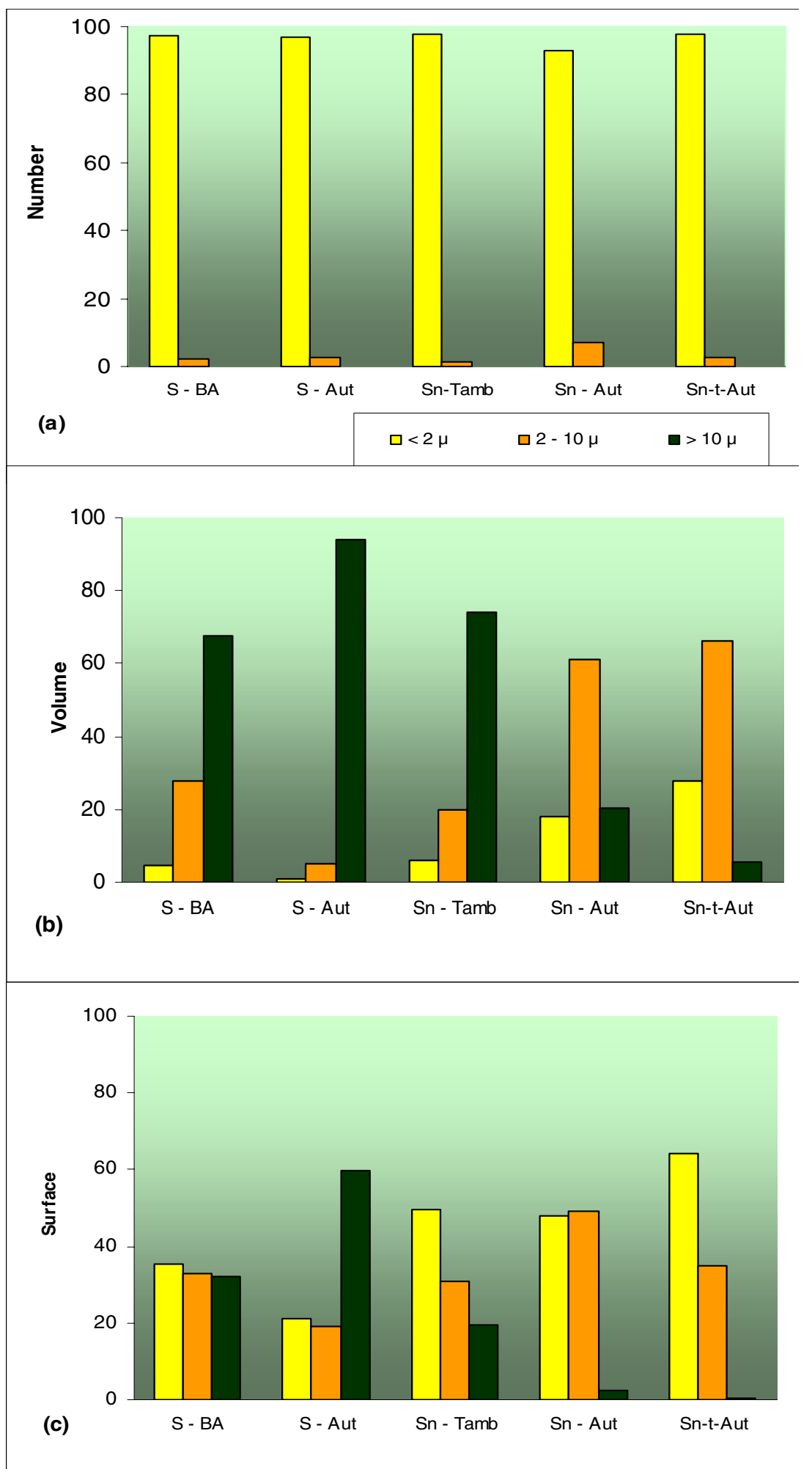

Figure I

Incidence of heating procedure (room temperature, water bath temperature and autoclave) in colloid formation. The particle distribution of $\mathrm{Sn}$ and S colloids was analyzed according to three parameters: (a) number, (b) volume and (c) surface area of the particles, grouped in three size ranges (lower than 2 microns, between 2 to 10 microns, higher than 10 microns). 


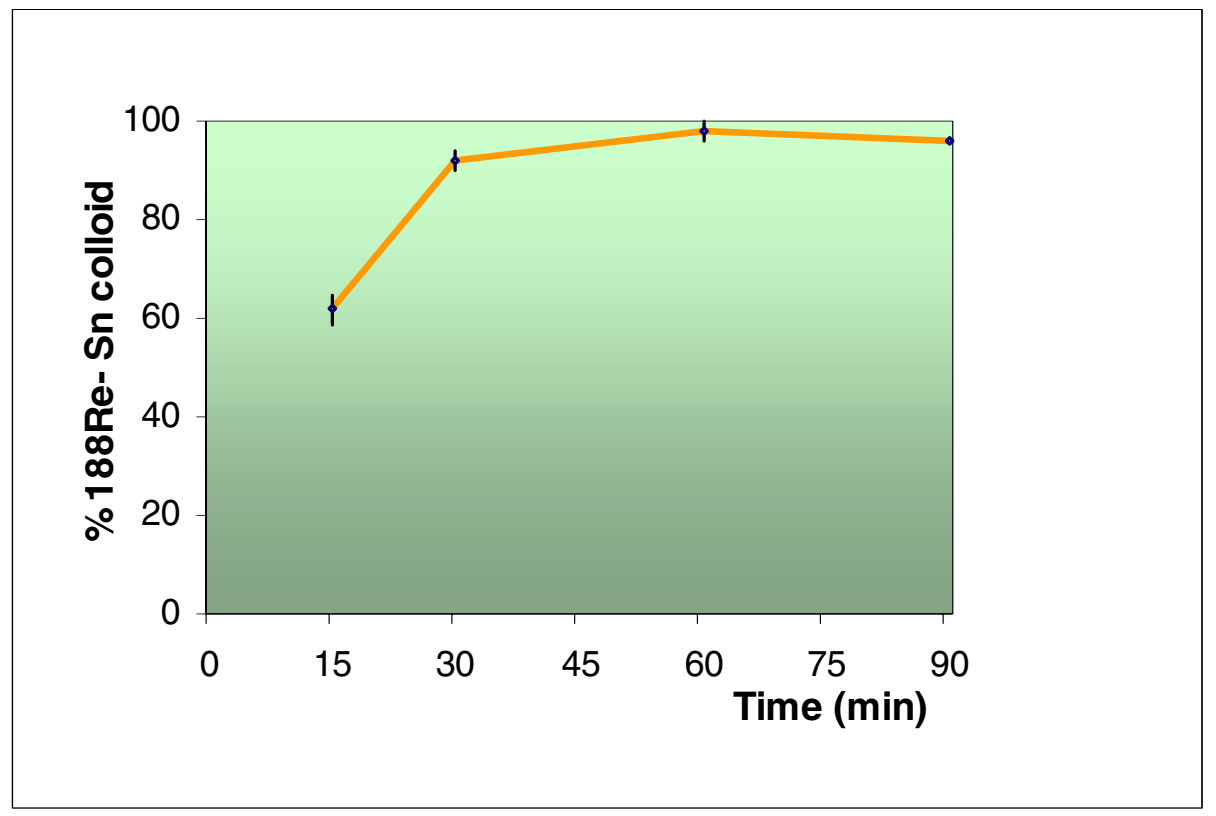

Figure 2

Labeled ${ }^{188} \mathrm{Re}-\mathrm{Sn}$ colloid vs. reaction time (minutes).

The ${ }^{188} \mathrm{Re}-\mathrm{S}$ was labeled by the addition of $500 \mu \mathrm{Ci}(18.5$ $\mathrm{MBq})$ of ${ }^{188} \mathrm{ReO}_{4}{ }^{-}$to the kit formulation described previously; then it was heated at $100^{\circ} \mathrm{C}$ for $30 \mathrm{~min}$. $\mathrm{pH}$ was adjusted to 8.0 with a phosphate buffer $0.2 \mathrm{M}$.

Radiochemical purity was determined by paper chromatography (Whatmann $\mathrm{N}^{\circ} 1$ ) using $0.9 \%$ saline solution as the mobile phase. Radioactivity was measured with a $\mathrm{Nal}(\mathrm{Tl})$ solid scintillation counter of $3 \times 3$ " (EG\&G ORTEC Multichannel Analizer).

\section{Physical characterization of the colloids}

The physical characterization of $\mathrm{Sn}$ and $\mathrm{S}$ colloids was measured adding a similar volume of $0.9 \%$ saline solution to the generator eluate for each kit formulation.

The number, volume and area of the colloid particles were analyzed with a laser diffraction particle size analyzer (Particle Size Analyzer Coulter ${ }^{\circledR}$ ).

Colloid particle size was also determined by membrane filtration, with serially connected filters of 1.2, 3 and 5 microns porous size (Sartorius ${ }^{\circledR}$ AG, cellulose nitrate filter).

The activity retained in each filter and filtrate was measured in a Capintec Radioisotope Calibrator (CRC-5R, calibration factor of 496).

\section{Stability studies}

In vitro and in vivo stability studies were performed for the Sn kit

\section{In vitro stability studies}

Two batches of the tin colloid kit with or without the tensoactive, kept at $2-8^{\circ} \mathrm{C}$ were studied for 60 days. At preset sampling times of $0,15,30,45$ and 60 days, the tin colloid was labeled, radiochemical purity was checked and characterization by laser diffraction and membrane filtration was done.

\section{In vivo stability studies}

Biodistribution in New Zealand adult rabbits (4-kg weight) were performed. The animals were sacrificed with an overdose of thiopental sodium after $48 \mathrm{hrs}$ of intraarticular administration of ${ }^{188} \mathrm{Re}-\mathrm{Sn}$ colloid $(500 \mu \mathrm{Ci} / \mathrm{mL}$, 18.5 MBq/mL). Articulation, liver, spleen, lungs, stomach, intestines, kidney, muscle, blood and urine samples were collected and radioactivity was measured in a $\mathrm{NaI}(\mathrm{Tl})$ scintillation counter $\left(\right.$ Ortec $\left.^{\circledR}\right)$, with a $3 \times 3$ " crystal.

This study was carried out at three times: 0, 30 and 60 days after batch preparation of the tin kit.

\section{Intrabatch variability}

Three batches of the tin kit were prepared at the same time, and physical parameters were determined as de- 


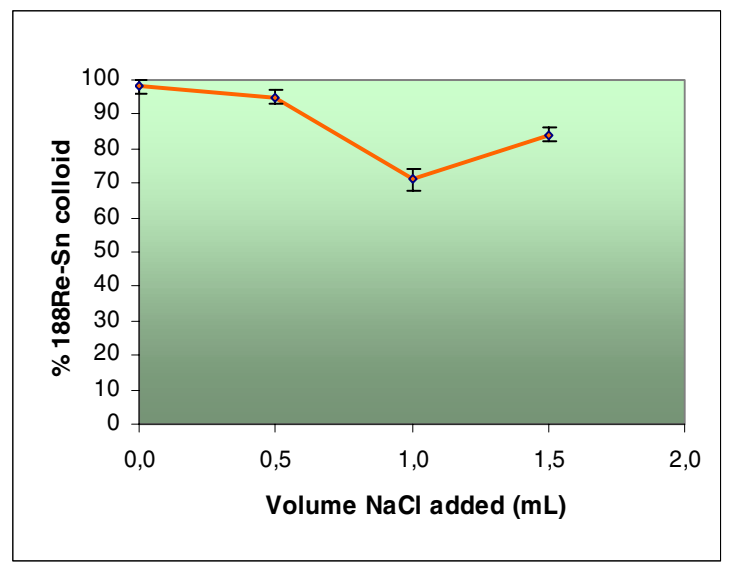

Figure 3

Labeled ${ }^{188} \mathrm{Re}-\mathrm{Sn}$ colloid vs. the added volume of saline solution $(\mathrm{mL})$.

scribed above, immediately after preparation and seven days afterwards.

\section{Scintigraphic studies}

The New Zealand rabbits were anesthetized by intramuscular administration of $50 \mathrm{mg} / \mathrm{kg}$ ketamine and $10 \mathrm{mg} / \mathrm{kg}$ of xilazine. Scintigrafic images were acquired with a Shopy Camera DSX CP, with medium energy collimator, at 0, 24 and 48 hours after intraarticular administration of the radiopharmaceutical.

\section{Results \\ Kit formulation}

The particle distribution of Sn and S colloids was analyzed according to three parameters: number, volume and surface area of the particles. For this purpose particle size were grouped in three ranges (lower than 2 microns, between 2 to 10 microns, higher than 10 microns), as is shown in Figure 1. The incidence of heating procedure (room temperature, water bath temperature and autoclave) in colloid formation is also shown. The number of particles of the two colloids did not differ (Figure 1a). The Sn colloid showed a better particle distribution than the $S$ colloid, when particle surface area or volumes of both preparations were considered. Figures 1(b) and 1(c).

\section{Labeling procedure optimization}

${ }^{188} \mathrm{Re}$-Sn colloid was obtained with a radiochemical purity higher than 90\% after autoclaving for $30 \mathrm{~min}$, and higher than $95 \%$ if heating was maintained for 1 hour (Figure 2 ). Since electrolytes might destabilize the colloid, the addition of a saline solution volume was evaluated. When the ratio (added volume/kit volume) was higher than two, the percentage of radiolabeled colloid was higher than $90 \%$, as is shown figure 3 .

\section{In vitro stability studies}

A three-dimensional plot representation (Figure 4) was chosen to show $\mathrm{Sn}$ colloid evolution immediately after preparation and 60 days afterwards (diameter on the $\mathrm{x}$-axis, particle number on the $y$-axis and either surface area or volume on the z-axis). Colloid aging produces an increase in the volume and surface of the smaller particles, as could be appreciated when they were shown in the selected ranges.

Besides this, the stability of a kit that had already been prepared was followed for 24 hours, and no significant changes were evident during this interval.

\section{Intrabatch variability}

The robustness of the product prepared in this manner was verified, showing minimal variation between 3 batches at $\mathrm{t}=0$. This behavior was maintained throughout the first week for all the batches.

\section{Radioactivity vs. particle distribution}

The ${ }^{188} \mathrm{Re}$-Sn colloid was analyzed by membrane filtration for 8 weeks after kit preparation and the distribution of the activity was plotted as a function of particle size grouped in four ranges $(<1.2$ microns, $1.2-3$ microns, 3 - 5 microns and $>5.0$ microns), as shown in figure 5 . It can be seen that more than $60 \%$ of the activity was found in particles bigger than 5 microns.

Particle size distribution was not affected by heating 30, 60 or $90 \mathrm{~min}$ as shown in figure 6.

\section{Methodologies for physical characterization of colloids}

As described above, two methodologies were used to characterize the physical parameters of colloids preparations: membrane filtration and laser diffraction. Figure $7 \mathrm{com}-$ pares results for the same colloid formulation studied by the two techniques. A great difference can be seen between the results obtained by the two methodologies immediately after kit preparation between both methodologies. This observation was in agreement with the fact that tin colloid variations were significant only during the first week and were detected by laser diffraction methodology but not by membrane filtration methodology.

\section{In vivo studies}

Figure 8 shows selected organ or tissue activity distribution, after 48 hours of ${ }^{188} \mathrm{Re}-\mathrm{Sn}$ (with or without tensoactive addition) intraarticular administration to New Zealand rabbits.

The scintigraphic image evidenced relevant activity only in the knee, and negligible activity in the rest of the organism. (Figure 9). 


\section{${ }^{188}$ Re-Sn kit stability}
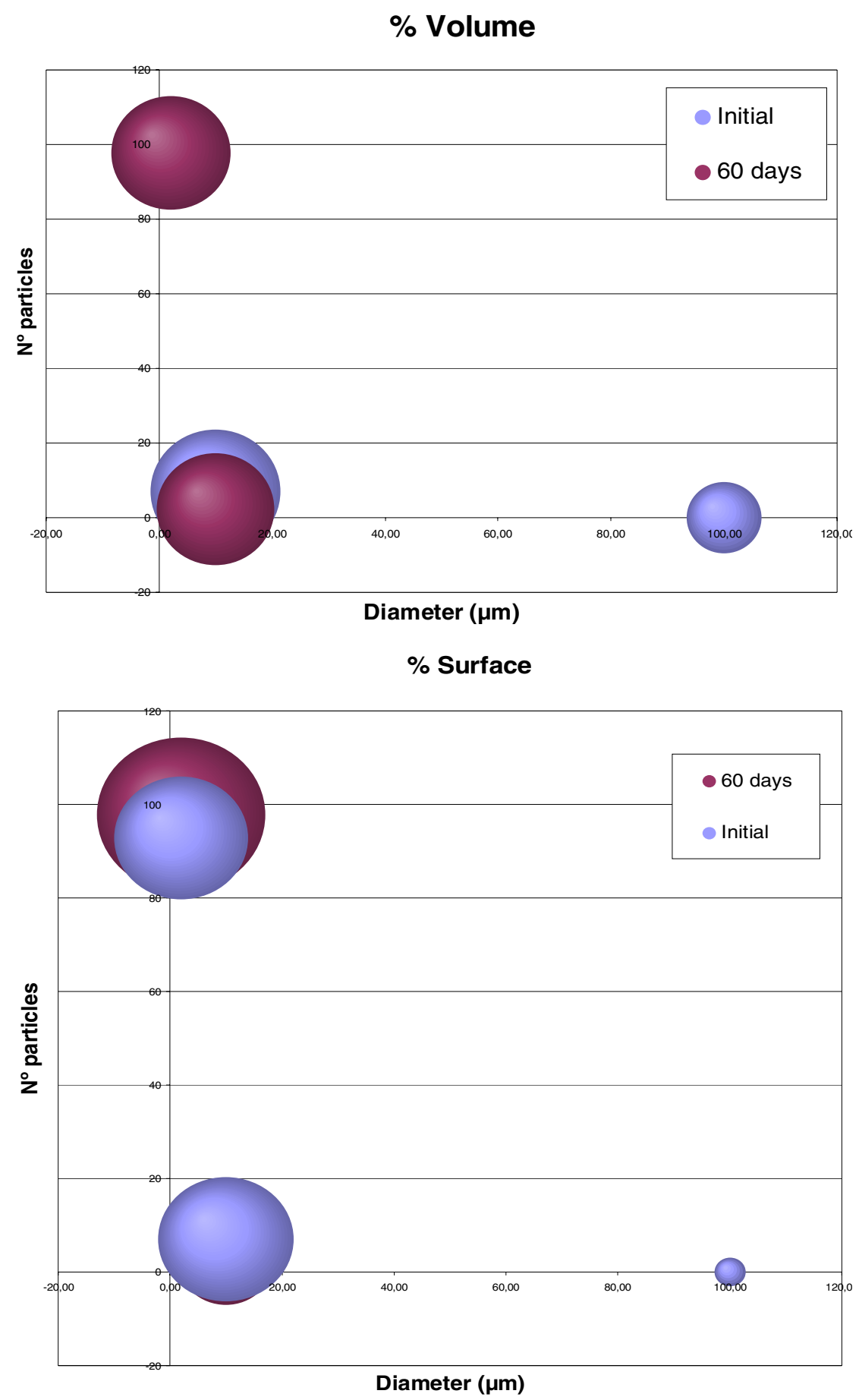

Figure 4

Three-dimensional plot representation of Sn colloid at time $=0$ and 60 days afterwards (diameter on the $x$-axis, particle number on the $y$-axis and either surface area or volume on the $z$-axis). 
188Re-Sn: Membrane Filtration

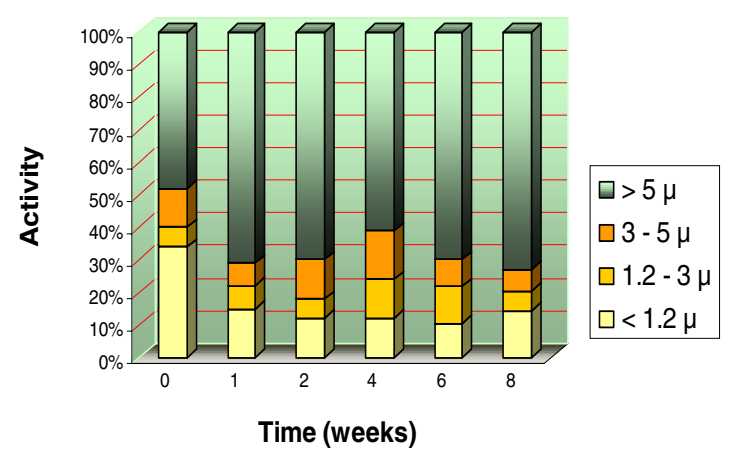

Figure 5

Activity distribution (\%) vs. time. The 188 Re-Sn colloid was analyzed by membrane filtration for 8 weeks after kit preparation and activity distribution was grouped in four ranges of particle size $(<1.2$ microns, 1.2 - 3 microns, 3 - 5 microns and $>5.0$ microns).

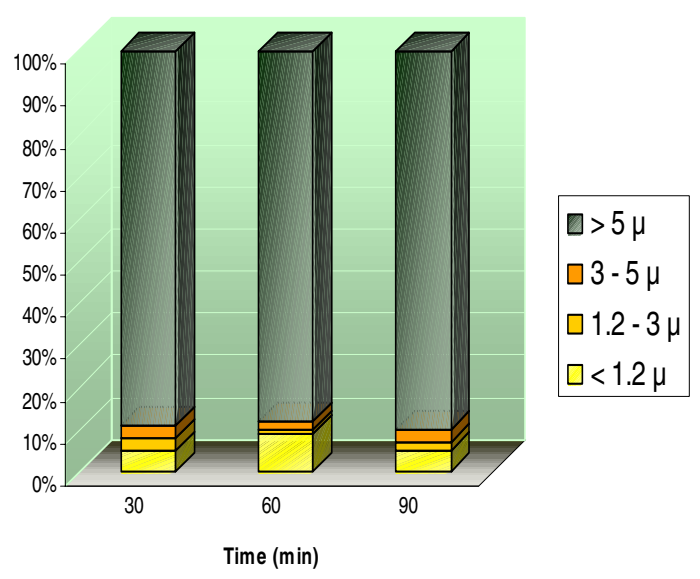

Figure 6

Activity distribution after heating 30,60 , and 90 minutes

\section{Discussion}

The physical characteristics of the Sn and S colloids obtained were analyzed to select the formulation, which showed the best parameters.

It has been well established by other investigators that the radiopharmaceutical particle size must be small enough to be phagocyted by the superficial cells of the synovium but not so small as to facilitate a fast biological clearance from the articulation $[12,13]$ was taken into account.

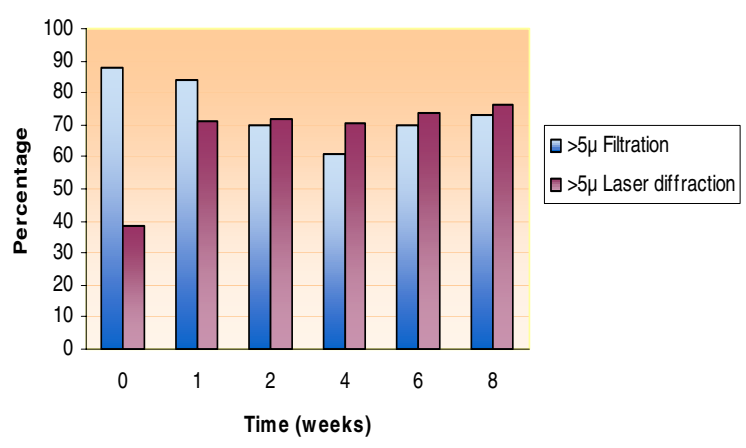

Figure 7

Methodology evaluation vs. time. Comparison of fractions over 5 microns obtained with membrane filtration or Coulter methodologies for 8 weeks after kit preparation.

Different optimal ranges of particle sizes considered as ideal for radiosynovectomy have been reported $[4,6,7,12,14,15]$. Differences found in the literature are probably based on the use of different methodologies to measure particle size. Other parameters were considered in our study, such as total particle volume or the sum of different volume sizes grouped in the ranges of interest. In the same way, another criteria were colloid surface area in selected ranges.

As radioactivity was deposited as a function of volume or surface of the particles, methodologies that put this into evidence and analyzed further modifications of the formulation in the same way should enable to arrive to consistent conclusions. It was found that in the 2-10 microns range, the $S n$ colloid attained a greater number, volume and surface are of particles than those of the S colloid.

Nearly 95\% of the S colloid volume belonged to those particles larger than 100 microns, in spite of the fact that these were a very small percentage of the whole preparation. On the other hand, $60 \%$ of the Sn colloid volume was composed of particles with size in the selected range, while only $5 \%$ of the volume of the $\mathrm{S}$ autoclaved colloid gave particles sizes in the same range.

Three-dimensional plot representation turned out to be an interesting tool to study valuable information about the behavior of colloids to study particle volume or surface area as a function of number, in a particular range. 


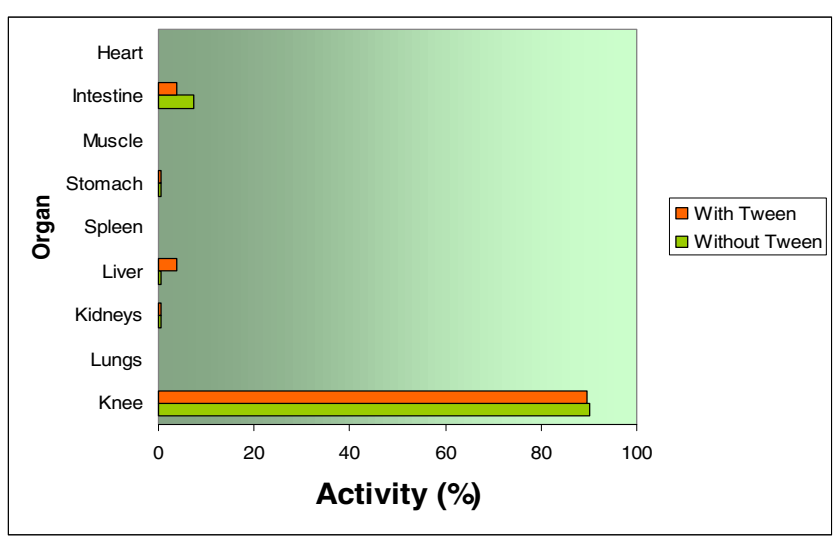

\section{Figure 8}

Selected organ or tissue activity distribution, after 48 hours intraarticular administration of ${ }^{188} \mathrm{Re}-\mathrm{Sn} 500 \mu \mathrm{Ci} / \mathrm{mL}$, (I8.5 $\mathrm{MBq} / \mathrm{mL})$ to New Zealand rabbits $(n=3)$ in articulation, heart, kidney, muscle and spleen.

The correlation of the two colloid characterization methodologies suggested that when a kit was evaluated by membrane filtration erroneous results might have been obtained, such as overestimation of particle percentage due to non-specific retention on the filter. This phenomenon was observed for those particles larger than 5 microns, immediately after kit preparation, where the electrical properties of the colloid were more significant. Besides that, only laser diffraction methodology provided a method to evaluate differences due to the aging of kit formulation during the first week after kit preparation and during the first 24 hours after similar conditions to those of labeling of tin colloid. This last observation made it possible to define a shelf life of 24 hours for the labeled colloid.

The effect of tensoactive addition was also studied (Tween $80^{\circledast}$ ) in order to facilitate radiopharmaceutical administration. It was thought that this addition would not diminish colloid stability due to counteract particle coalition. It is known that small particles will show a gradual increase in size, a phenomenon that is called Ostwald maturation [16]. Smaller particles have a greater solubility than larger ones of the same preparation, due to their higher surface area and free superficial energy. Spontaneous enlargement of colloidal dispersions due to aging, is accelerated by an increase in precipitate solubility and may be delayed by diminishing their solubility or by adding very small amounts of tensoactive agents that are absorbed on the surface of the particle. Taking this into account, Tween 80 was added to the formulation, but re-
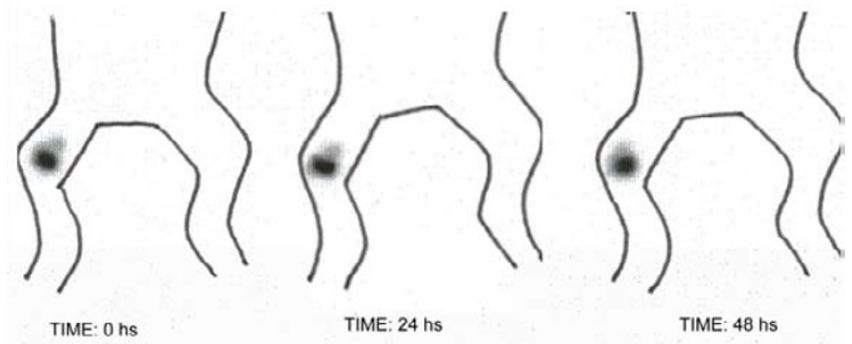

Figure 9

Scintigraphic images at 0,24 and 48 hrs after intraarticular administration of $500 \mu \mathrm{Ci} / \mathrm{mL}^{188} \mathrm{Re}-\mathrm{Sn},(18.5 \mathrm{MBq} / \mathrm{mL})$ to New Zealand rabbits.

sults were different to those described above because particle volume showed an increase after kit preparation.

The radiochemical purity of the ${ }^{188}$ Re-Sn colloid showed an increase after heating the colloid from thirty to sixty minutes. This fact implied a slow reaction, which required this time to reach the best value (95\%). Activity distribution in the different ranges of particle size was not affected by heating time. Activity absorption on each particle is an unspecific process. Eighty percent of the activity was kept in those particles retained by the 5 microns filter - for heating time of 30,60 or $90 \mathrm{~min}-$, and these particles were a small amount of the total preparation. Ninety eight percent of particles, in number, had sizes below 3 microns and concentrated only about $10 \%$ of the whole activity. This fact confirmed to us that particle volume or surface area were the main parameters to be taken into account. Therefore particle size distribution did not correlate with activity data distribution.

More important changes in particle distribution were detected during the first week after kit preparation, this being the time needed for colloid stabilization. No further relevant changes were noted during the stability study so that eight weeks of shelf life could be safely proposed.

In vivo studies have shown that 48 hours post-administration knee retention was higher than $90 \%$. One and three percent of activity was detected in the kidney and liver respectively, which can be attributed to the smallest particles (less than 1 micron); activities of urine samples were at background levels. 


\section{Conclusions}

One of the most important characteristics of a radiopharmaceutical for synovectomy is to deliver a radiation dose in the target tissue, and if there is any leakage from the joint this should be insignificant. Good stability and low cost are also very important features.

The ${ }^{188}$ Re-Sn colloid fulfilled both objectives, which makes it an attractive radiotherapeutical agent for rheumatoid arthritis treatment in the knee. Forty-eight hours after administration, nearly $90 \%$ of the total radiation remained inside the knee joint.

The ${ }^{188} \mathrm{~W} /{ }^{188}$ Re generator, with a shelf life of six months, had a suitable performance for this clinical application.

The three-dimensional plot representation of colloid physical characteristics offered valuable information, both qualitative and quantitative, about colloid particle behavior. This was very important because particles smaller than 2 microns, numerically made up more than $90 \%$ of the whole preparation, but the activity remained adsorbed by the bigger ones, which could be retained and/ or phagocyted inside the joint. Distribution by particle size was the least suitable characterization for detecting minor differences between the two preparations. If the membrane filtration method alone had been used for detecting activity distribution on colloid particles, wrong conclusions might have been reached. The laser diffraction method allowed us to observe changes in volume or surface area in colloid particles through time and to determine slight variations in these parameters.

Physical characterization by laser diffraction was proved to be a valuable tool for radiopharmaceutical colloid formulations.

\section{Competing interests}

None declared.

\section{Authors' contributions}

MCU participated in the design of the radiopharmaceutical, carried out the pharmaceutical experiments and drafted the manuscript.

ES planned the study and performed its coordination. He also drafted the manuscript.

AM performed the Coulter Analizer determinations.

MF performed the experimental animal studies.

AP carried out the scintigraphic studies.

JG responsible for the scintigraphic studies.
All authors read and approved the final manuscript.

\section{Abbreviations}

BA, water bath; Aut, autoclave; Tamb, room temperature; $\mathrm{t}$, tensoactive.

\section{Acknowledgements}

The authors wish to thank PEDECIBA Química for its financial support.

\section{References}

I. Rosenthall L: Use of radiocolloids for intraarticular therapy for synovitis. In: Therapy in nuclear medicine (Edited by: Spencer RP) New York: Grune \& Stratton 1978, 147-242

2. Harbert JC: Radiocolloid therapy in joint disease In: Nuclear medicine therapy (Edited by: Harbert JC) New York: Thieme Medical 1987, 169-186

3. Doherty M: Potential rheumatologic applications of intra-articular radiocolloid therapy Geriatric Medicine Today 1984, 3:3 I-42

4. Davis MA, Chinol M: Radiopharmaceuticals for radiation synovectomy: evaluation of two yttrium-90 particulate agent J Nucl Med 1989, 30:1047-1055

5. Murray $\mathrm{T}$, Erskine Hilditch $\mathrm{T}$ : Therapeutic applications of radiopharmaceuticals In: Textbook of Radiopharmacy. Theory and Practice (Edited by: Charles B Sampson) Gordon and Breach Science Publishers I999, 380

6. Wang SJ, Lin WY, Hsieh BT, Shen LH, Tsai ZT, Ting G, Knapp FF Jr: Rhenium- 188 sulphur colloid as a radiation synovectomy agent. Eur J Nucl Med 1995, 22(6):505-7

7. Venkatesan P, Shortkroff S, Zalutsky MR, Sledge CB: Rhenium heptasulfide: a potential carrier system for radiation synovectomy. Nucl Med Biol 1990, 4:293-357

8. Johnson LS, Yanch JC, Shortkoff CL, Barnes AI, Sledge CB: Beta-particle dosimetry in radiation synovectomy. Eur J Nucl Med 1995, 22(9):977-988

9. Kamioki H, Mirzadeh S, Lambrecht RM, Knapp FF Jr, Dadachova K: ${ }^{188} \mathrm{~W} / \mathbf{I}^{188}$ Re generator for biomedical applications. Radiochimica Acta 1994, 65:39-46

10. Knapp FF Jr, Mirzadeh S, Beets AL, O'Doherty M, Blower PJ, Verdera ES, Gaudiano JP, Kropp J, Guhlke H, Palmedo H, Biersack HJ: Reactor-produced radioisotopes from ORNL for bone pain palliation. Appl Radiat Isot 1998, 49:309-315

II. Jeong JM, Lee YJ, Kim YJ, Chang YS, Lee DS, Chung JK, Song YW, Lee MC: Preparation of rhenium- 88 -tin colloid as a radiation synovectomy agent and comparison with rhenium- I88-sulfur colloid. Appl Rad Isotopes 2000, 52:85 I-855

12. Shortkroff S, Sledge CB: Radiation synovectomy. In: Principles of Nuclear Medicine (Edited by: Wagner HN Jr, Szabo Z, Buchanan JW) WB Saunders Co. Philadelphia 1995, 1021-1028

13. Noble J, Jones AG, Davies MA, Sledge CB, Kramer RI, Livni E: Leakage of radioactive practice system from synovial joint studied with a gamma camera; its application to radiation synovectomy. J Bone Joint Surg [Am] 1983, 65:38I-389

14. Chinol M, Vallabhajosula S, Goldsmith S, Klein M, Deutsch K, Chinen L, Brodack J, Deutsch E, Watson B, Tofe A: Chemistry and biological behaviour of Samarium-I53 and Rhenium-I86 labeled hydroxyapatite particles: potential radiopharmaceuticals for radiation synovectomy. I Nucl Med 1993, 34(9): I 536-1542

I5. Clunie G, Lui D, Edwards J, Ell P: Samarium-I53 particulate hydroxyapatite radiation synovectomy: biodistribution data for chronic knee synovitis. J Nucl Med 1995, 36:5 I-57

16. Schott H: Dispersiones coloidales. In Remington: Ciencia y Práctica de la Farmacia (Edited by: Editado por Alfonso Genaro Editores) Médica Panamericana 1997, 366-404

\section{Pre-publication history}

The pre-publication history for this paper can be accessed here:

http://www.biomedcentral.com/1471-2385/2/1/prepub 